\title{
Tuning the Microstructures of Decavanadate-based Supramolecular Hybrids via Regularly Changing the Spacers of Bis(triazole) Ligands
}

Mo Wang ${ }^{a}$, Wenlong $\operatorname{Sun}^{a}$, Haijun Pang ${ }^{a *}$, Huiyuan Ma ${ }^{a * *}$, Jia Yu ${ }^{a, b}$, Zhuanfang Zhang $^{a}$, Ying Niu ${ }^{a}$, Mingming Yin $^{c}$

${ }^{a}$ Key Laboratory of Green Chemical Engineering and Technology of College of

Heilongjiang Province, College of Chemical and Environmental Engineering, Harbin University of Science and Technology, Harbin 150040, China

${ }^{b}$ College of Aerospace and Civil Engineering, Harbin Engineering University, Harbin, 150001, China

${ }^{c}$ Jiamusi Electric Machine Co., Ltd. 766 Guangfu Road, Jiamusi City, 154002, China

28 pages

10 Figures

1 Scheme

1 table

*Correspondence to: H.J. Pang, Tel./fax.: +86-451-86688575;

**Correspondence to: H.Y. Ma, Tel./fax: +86-0451-86392716;

E-mail addresses: panghj116@163.com, mahy017@163.com. 


\section{Abstract}

With tuning the ligands from bte, btp, btb to bth, four new decavanadate-based metal-organic hybrid compounds, [Zn(bte $\left.)\left(\mathrm{H}_{2} \mathrm{O}\right)_{4}\right]\left[\mathrm{Zn}_{2}(\right.$ bte $\left.)\left(\mathrm{H}_{2} \mathrm{O}\right)_{10}\right]\left(\mathrm{V}_{10} \mathrm{O}_{28}\right) \cdot 8 \mathrm{H}_{2} \mathrm{O}$, $\left[\mathrm{Zn}_{2}(\mathrm{btp})_{4}\left(\mathrm{H}_{2} \mathrm{O}\right)_{6}\right]\left(\mathrm{H}_{2} \mathrm{~V}_{10} \mathrm{O}_{28}\right) \cdot 4 \mathrm{H}_{2} \mathrm{O}, \quad\left[\mathrm{Zn}\left(\mathrm{H}_{2} \mathrm{O}\right)_{6}\right]\left[\mathrm{Zn}_{2}(\mathrm{btb})_{2} \mathrm{~V}_{10} \mathrm{O}_{28}\left(\mathrm{H}_{2} \mathrm{O}\right)_{6}\right] \cdot 4 \mathrm{H}_{2} \mathrm{O}$, and $\left[\mathrm{Zn}_{2}(\right.$ bth $\left.)\left(\mathrm{H}_{2} \mathrm{O}\right)_{10}\right]\left(\mathrm{H}_{2} \mathrm{~V}_{10} \mathrm{O}_{28}\right) \cdot 6 \mathrm{H}_{2} \mathrm{O}$ (bte = 1,2-bis(1,2,4-triazol-1-yl)ethane, btp = 1,3-bis(1,2,4-triazol-1-y1)propane, btb $=$ 1,4-bis(1,2,4-triazol-1-y1)butane, bth $=$ 1,6-bis(1,2,4-triazol-1-y1)hexane), have been synthesized under conventional conditions. The four compounds represent the first examples of decavanadate-based metal-organic hybrids constructed by Zn-bis(triazole) complexes. Their structural analyses show that the four compounds possess different $\mathrm{Zn}$-bis(triazole) structural motifs and various finally structures, which verifies that regular changing the spacers of ligands is an effective strategy to tuning the structures of polyoxometalate-based hybrids. Also, the electrochemical studies show that the compounds have good electrocatalytic activities towards oxidation of nitrite molecules ascribed to V-centers. Keywords: Decavanadate; "pinwheel" striped structure; spacer length of ligand; electrochemical property. 


\section{Introduction}

Inorganic-organic hybrid compounds are new generation of solid-state materials that have promising applications in catalysis, gas adsorption and separation, energy storage devices and porous materials owing to their chemical and structural diversity [1-4]. In recent years, some new synthetic methods, such as surfactant-thermal method, have been used in the preparation of crystalline inorganic-organic hybrid materials [5]. It is clear that the exploration of new synthetic strategies always speeds up the advancement of inorganic-organic hybrids, more and more new structures with diverse properties would be anticipated [6-12]. Currently, widespread interest in polyoxometalate (POM) chemistry is focused on the modification and functionalization of polyoxoanions by transition metal complexes (TMCs) through their terminal or bridging oxygen atoms to extend their structural multiplicity and versatility, leading to novel species that conflate useful properties of POMs and TMCs components, providing access to a vast area of complexes, multifunctional materials [13-17]. Many chemists have paid great attention to the rational design and synthesis of such compounds [18-21]. These efforts have achieved significant progress, and many such compounds have been obtained by selecting the appropriate POMs as building blocks, such as Keggin- [22-24], Dawson- [25, 26], Anderson- [27, 28], metatungstate- [29, 30], and octamolybdate-type POMs [31, 32]. However, compared with other POMs, hybrids constructed by decavanadates have been rarely reported so far.

Decavanadates as a subclass of the family of POMs, are excellent inorganic 
building blocks to obtain novel vanadate-based hybrid compounds not only because of their abundant structural diversity but also due to their versatile physical and chemical properties, such as reversible redox behavior [33]. It is well known that there are three kinds of decavanadates: $\left[\mathrm{V}_{10} \mathrm{O}_{28}\right]^{6-}, \quad\left[\mathrm{V}_{10} \mathrm{O}_{26}\right]^{4-}$ and $\left[\mathrm{V}_{10} \mathrm{O}_{25}\right]^{4-}$ (abbreviations to $\mathrm{V}_{10} \mathrm{O}_{28}, \mathrm{~V}_{10} \mathrm{O}_{26}$, and $\mathrm{V}_{10} \mathrm{O}_{25}$, respectively). Especially the ball-shaped $\mathrm{V}_{10} \mathrm{O}_{28}$ cluster has drawn more attention than other decavanadate clusters [34-38]. Nevertheless, the compounds that consist of $\mathrm{V}_{10} \mathrm{O}_{28}$ clusters linked to TMCs or organic cations have been rarely reported up to now [33-50] (The summarization of typical compounds constructed by $\mathrm{V}_{10} \mathrm{O}_{28}$ clusters are listed in Table S1, Supporting Information). Thus, the design and synthesis of such $\mathrm{V}_{10} \mathrm{O}_{28}$-based hybrid compounds remain a challenge.

An important factor in designing hybrid compounds rationally is the judicious choice of organic ligands. Ligands play a crucial role in the assembly of hybrid compounds as their structural features and chemical properties determine potential functionalities of the eventual structures. Recently, flexible bis(pyridine)/bis(imidazole)/bis(triazole) ligands, which can provide multiple coordination sites and possess versatile coordination modes and conform to the coordination environments of transition-metal ions and/or POMs, have attracted great attention in the design and construction of vanadate-based compounds [33, 51-54]. For example, the flexible 1,1'-(1,4-butanediyl)bis(imidazole) (abbr. bbi) ligand was used to construct POM-templated architectures based on $\alpha-\left[\mathrm{As}_{8} \mathrm{~V}_{14} \mathrm{O}_{42}\left(\mathrm{H}_{2} \mathrm{O}\right)\right]^{4-}$ anions [51], and chiral architectures based on $\mathrm{V}_{10} \mathrm{O}_{26}$ anions [52]. Sparked by these examples, 
a series of flexible bis(triazole) ligands, namely bte, btp, btb and bth (bte = 1,2-bis(1,2,4-triazol-1-yl)ethane, btp $=$ 1,3-bis(1,2,4-triazol-1-y1)propane, btb = 1,4-bis(1,2,4-triazol-1-y1)butane, bth = 1,6-bis(1,2,4-triazol-1-y1)hexane), have been introduced into $\mathrm{V}_{10} \mathrm{O}_{28}$ and $\mathrm{Zn}^{2+}$ reaction system based on following considerations: (i) the 1,2,4-triazole group, with three $\mathrm{N}$ donors, is an integration of the coordination geometry of both imidazoles and pyrazoles to provide more potential coordination sites; (ii) The two 1,2,4-triazole rings can freely twist around the $-\left(\mathrm{CH}_{2}\right)_{\mathrm{n}}$ - group to meet the requirements of the coordination geometries of metal atoms in the assembly process; (iii) The $-\left(\mathrm{CH}_{2}\right)_{\mathrm{n}}$ - spacers in the ligands are changeable. It is easy to control artificially [25, 53-59]. So far, the use of bte, btp, btb and bth as ligands to construct hybrid compounds based on $\mathrm{V}_{10} \mathrm{O}_{28}$ POMs has not been fully realized.

Taking this into account, by trying different synthetic conditions and performing many experiments, four hybrid compounds based on $\mathrm{V}_{10} \mathrm{O}_{28}$ clusters, $\left[\mathrm{Zn}(\right.$ bte $\left.)\left(\mathrm{H}_{2} \mathrm{O}\right)_{4}\right]\left[\mathrm{Zn}_{2}(\right.$ bte $\left.)\left(\mathrm{H}_{2} \mathrm{O}\right)_{10}\right]\left(\mathrm{V}_{10} \mathrm{O}_{28}\right) \cdot 8 \mathrm{H}_{2} \mathrm{O}$

$\left[\mathrm{Zn}_{2}(\mathrm{btp})_{4}\left(\mathrm{H}_{2} \mathrm{O}\right)_{6}\right]\left(\mathrm{H}_{2} \mathrm{~V}_{10} \mathrm{O}_{28}\right) \cdot 4 \mathrm{H}_{2} \mathrm{O} \quad(\mathbf{2}), \quad\left[\mathrm{Zn}\left(\mathrm{H}_{2} \mathrm{O}\right)_{6}\right]\left[\mathrm{Zn}_{2}(\mathrm{btb})_{2} \mathrm{~V}_{10} \mathrm{O}_{28}\left(\mathrm{H}_{2} \mathrm{O}\right)_{6}\right] \cdot 4 \mathrm{H}_{2} \mathrm{O}$ (3), and $\left[\mathrm{Zn}_{2}(\mathrm{bth})\left(\mathrm{H}_{2} \mathrm{O}\right)_{10}\right]\left(\mathrm{H}_{2} \mathrm{~V}_{10} \mathrm{O}_{28}\right) \cdot 6 \mathrm{H}_{2} \mathrm{O}$ (4) have been conventionally synthesized (Scheme 1). The four compounds exhibit supramolecular architectures, and the structural analyses of these compounds show that the spacer length of ligands is a key factor to control the structures of the hybrid compounds. Furthermore, the electrocatalytic properties of the hybrid compounds were investigated. 


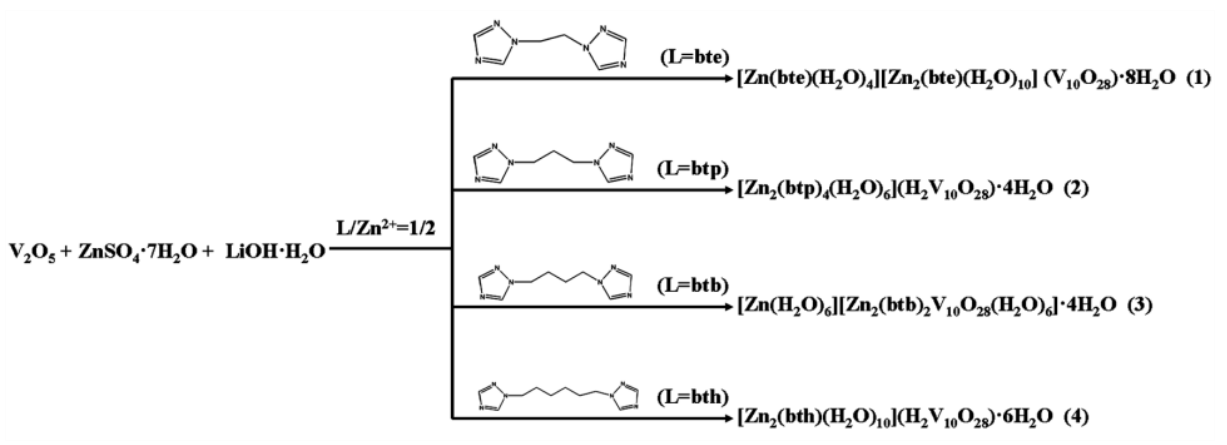

Scheme 1 Preparation routes for compounds 1-4.

\section{Experimental Section}

\subsection{Materials and General Methods}

All reagents and solvents for syntheses were purchased from commercial sources and used as received without further purification. Elemental analyses $(\mathrm{C}, \mathrm{H}$ and $\mathrm{N})$ were performed on a Perkin-Elmer $2400 \mathrm{CHN}$ Elemental Analyzer, and that of V and Zn were analyzed on a Plasm-spec(I) ICP atomic emission spectrometer. The IR spectra were recorded in the range of $4000-400 \mathrm{~cm}^{-1}$ on an Alpha Centaurt FT/IR spectrophotometer using $\mathrm{KBr}$ pellets. $\mathrm{TG}$ analyses were recorded by using a Perkin-Elmer TGA7 instrument in an atmosphere of nitrogen at a heating rate of $10{ }^{\circ} \mathrm{C} / \mathrm{min}$. A CHI 760D electrochemical workstation was used for control of the electrochemical measurements and data collection. A conventional three-electrode system was used, with a modified carbon paste electrode (CPE) as a working electrode, a twisted platinum wire as counter electrode and a commercial $\mathrm{Ag} / \mathrm{AgCl}$ as a reference electrode.

\subsection{Synthesis of $\left[\mathrm{Zn}(\right.$ bte $\left.)\left(\mathrm{H}_{2} \mathrm{O}\right)_{4}\right]\left[\mathrm{Zn}_{2}(\right.$ bte $\left.)\left(\mathrm{H}_{2} \mathrm{O}\right)_{10}\right]\left(\mathrm{V}_{10} \mathrm{O}_{28}\right) \cdot 8 \mathrm{H}_{2} \mathrm{O}(1)$}

A mixture of $\mathrm{V}_{2} \mathrm{O}_{5}(0.151 \mathrm{~g}, 0.8 \mathrm{mmol}), \mathrm{ZnSO}_{4} \cdot 7 \mathrm{H}_{2} \mathrm{O}(0.151 \mathrm{~g}, 0.5 \mathrm{mmol})$, 
$\mathrm{LiOH} \cdot \mathrm{H}_{2} \mathrm{O}(0.061 \mathrm{~g}, 1.5 \mathrm{mmol})$ and bte $(0.052 \mathrm{~g}, 0.3 \mathrm{mmol})$ was dissolved in $8 \mathrm{~mL}$ of distilled water at room temperature. The mixture was stirred for $c a .1 \mathrm{~h}$ until it was homogeneous. Then the $\mathrm{pH}$ value of the mixture was adjusted to about 4.1 with $3 \mathrm{M}$ acetic acid. After removal of the precipitate by filtration, the clear solution was allowed to evaporate in the air at room temperature. Seven days later, some yellow block crystals of compound 1 were obtained. Yield: $40 \%$ (based on Zn). Anal. calc. for 1: H, 3.22; C, 7.67; N, 8.95; Zn, 10.45; V, 27.12 (\%). Found: H, 3.24; C, 7.70; N, 8.94; Zn, 10.25; V, $27.05(\%)$.

2.3. Synthesis of $\left[\mathrm{Zn}_{2}(\text { btp })_{4}\left(\mathrm{H}_{2} \mathrm{O}\right)_{6}\right]\left(\mathrm{H}_{2} \mathrm{~V}_{10} \mathrm{O}_{28}\right) \cdot 4 \mathrm{H}_{2} \mathrm{O}$ (2)

Compound 2 was prepared similar to 1, except that btp (0.054 g, $0.3 \mathrm{mmol})$ was used instead of bte. Yellow crystals of 2 were obtained in a yield of $28 \%$ based on $\mathrm{Zn}$. Anal. calc. for 2: H, 3.15; C, 16.96; N, 16.95; Zn, 6.60; V, 25.69 (\%). Found: H, 3.21; C, 16.88; N, 16.75; Zn, 6.54; V, $25.76(\%)$.

\subsection{Synthesis of $\left[\mathrm{Zn}\left(\mathrm{H}_{2} \mathrm{O}\right)_{6}\right]\left[\mathrm{Zn}_{2}(b t b)_{2} \mathrm{~V}_{10} \mathrm{O}_{28}\left(\mathrm{H}_{2} \mathrm{O}\right)_{6}\right] \cdot 4 \mathrm{H}_{2} \mathrm{O}$ (3)}

Compound 3 was prepared similar to 1, except that btb $(0.053 \mathrm{~g}, 0.3 \mathrm{mmol})$ was used instead of bte. Yellow crystals of $\mathbf{3}$ were obtained in a yield of $39 \%$ based on $\mathrm{Zn}$;. Anal. calc. for 3: H, 3.09; C, 10.52; N, 9.20; Zn, 10.74; V, 27.89 (\%). Found: H, 3.12; C, 10.50; N, 9.18; Zn, 10.80; V, $27.78(\%)$.

\subsection{Synthesis of $\left[\mathrm{Zn}_{2}(\right.$ bth $\left.)\left(\mathrm{H}_{2} \mathrm{O}\right)_{10}\right]\left(\mathrm{H}_{2} \mathrm{~V}_{10} \mathrm{O}_{28}\right) \cdot 6 \mathrm{H}_{2} \mathrm{O}$ (4)}

Compound 4 was prepared similar to 1 , except that bth $(0.056 \mathrm{~g}, 0.3 \mathrm{mmol})$ was used instead of bte. Yellow crystals of $\mathbf{4}$ were obtained in a yield of $36 \%$ based on $\mathrm{Zn}$. Anal. calc. for 4: H, 3.15; C, 7.51; N, 5.26; Zn, 8.18; V, 31.86 (\%). Found: H, 3.06; C, 
7.30; N, 5.40; Zn, 8.40; V, $32.25(\%)$.

\subsection{X-ray Crystallographic Study}

The single-crystal X-ray diffraction data collections of compounds 1-4 were performed using a Bruker Smart Apex CCD diffractometer (Bruker Corporation, Germany) with Mo-K $\alpha$ radiation $(\lambda=0.71073 \AA)$ at $296 \mathrm{~K}$ respectively. Empirical absorption corrections were applied. All the structures were solved by the directed methods and refined by full-matrix least-squares on $\mathrm{F}^{2}$ using the SHELXTL-97 crystallographic software package $[60,61]$. The atoms C4 and C5 of bth ligands in compound $\mathbf{4}$ are disordered. All non-hydrogen atoms were refined anisotropically except disordered atoms $\mathrm{C} 4$ and $\mathrm{C} 5$ in compound 4. The hydrogen atoms attached to carbon atoms in all compounds were generated geometrically. The hydrogen atoms attached to $\mathrm{C} 2, \mathrm{C} 4$ and $\mathrm{C} 5$ in compound 4 are not added, due to the disorder of $\mathrm{C} 4$ and C5 atoms. The hydrogen atoms attached to water molecules were not located but were also included in the formula calculations. A summary of the crystal data, data collection, and refinement parameters for 1-4 are listed in Table 1. Crystallographic data for compounds 1-4 have been deposited in the Cambridge Crystallographic Data Center with CCDC Numbers of 1430969 (1), 1430970 (2), 1430971 (3), 1430972 (4).

Table 1 Crystal data and structure refinements for compounds 1-4.

\begin{tabular}{lllll}
\hline Compounds & $\mathbf{1}$ & $\mathbf{2}$ & $\mathbf{3}$ & $\mathbf{4}$ \\
\hline Formula & $\mathrm{C}_{12} \mathrm{H}_{60} \mathrm{Zn}_{3} \mathrm{~N}_{12} \mathrm{O}_{50} \mathrm{~V}_{10}$ & $\mathrm{C}_{28} \mathrm{H}_{62} \mathrm{Zn}_{2} \mathrm{~N}_{24} \mathrm{O}_{38} \mathrm{~V}_{10}$ & $\mathrm{C}_{16} \mathrm{H}_{56} \mathrm{Zn}_{3} \mathrm{~N}_{12} \mathrm{O}_{44} \mathrm{~V}_{10}$ & $\mathrm{C}_{10} \mathrm{H}_{50} \mathrm{Zn}_{2} \mathrm{~N}_{6} \mathrm{O}_{44} \mathrm{~V}_{10}$ \\
$M \mathrm{r}$ & 1878.30 & 1983.16 & 1826.31 & 1598.75 \\
$\mathrm{~T} / \mathrm{K}$ & $296(2)$ & $296(2)$ & $296(2)$ & $296(2)$ \\
Crystal & Triclinic & Triclinic & Triclinic & Triclinic \\
Space group & $P \overline{1}$ & $P \overline{1}$ & $P \overline{1}$ & $P \overline{1}$
\end{tabular}




\begin{tabular}{|c|c|c|c|c|}
\hline$a / \AA ̊$ & $11.7187(9)$ & $9.951(5)$ & $10.838(5)$ & $8.871(5)$ \\
\hline$b / \AA$ & 11.8894(9) & $10.817(5)$ & $11.934(5)$ & $10.213(5)$ \\
\hline$c / \AA$ & $12.8895(10)$ & $15.729(5)$ & $12.293(5)$ & $15.850(5)$ \\
\hline$\alpha /^{\circ}$ & $76.098(1)$ & $78.366(5)$ & $94.944(5)$ & $74.234(5)$ \\
\hline$\beta /^{\circ}$ & $72.933(1)$ & $81.200(5)$ & $111.881(5)$ & $86.443(5)$ \\
\hline$\gamma /{ }^{\circ}$ & $63.313(1)$ & $78.845(5)$ & $107.708(5)$ & $66.979(5)$ \\
\hline$V / \AA^{3}$ & $1521.5(2)$ & $1615.5(12)$ & $1369.3(10)$ & $1270.3(10)$ \\
\hline$Z$ & 1 & 1 & 1 & 1 \\
\hline$\mu / \mathrm{mm}^{-1}$ & 2.733 & 2.214 & 3.027 & 2.786 \\
\hline$F(000)$ & 892.0 & 970.0 & 876.0 & 748.0 \\
\hline$D_{\text {calcd }} / \mathrm{g} \mathrm{cm}^{-3}$ & 2.001 & 2.016 & 2.176 & 2.029 \\
\hline Refl. & 7940 & 10443 & 7216 & 6652 \\
\hline \multicolumn{5}{|l|}{ Measured } \\
\hline Refl. Unique & 5462 & 5753 & 4894 & 4568 \\
\hline$R_{\text {int }}$ & 0.0200 & 0.0119 & 0.0183 & 0.0192 \\
\hline GoF on $F^{2}$ & 0.904 & 1.172 & 1.154 & 1.036 \\
\hline $\begin{array}{l}R_{1}{ }^{a} / w R_{2}^{b} \\
{[I>2 \sigma(I)]}\end{array}$ & $0.0601 / 0.2219$ & $0.0429 / 0.1827$ & $0.0414 / 0.1491$ & $0.0513 / 0.1663$ \\
\hline
\end{tabular}

\section{Results and Discussion}

\subsection{Structure description}

\subsection{1. [ $\mathrm{Zn}($ bte $\left.)\left(\mathrm{H}_{2} \mathrm{O}\right)_{4}\right]\left[\mathrm{Zn}_{2}(\right.$ bte $\left.)\left(\mathrm{H}_{2} \mathrm{O}\right)_{10}\right]\left(\mathrm{V}_{10} \mathrm{O}_{28}\right) \cdot 8 \mathrm{H}_{2} \mathrm{O}(1)$}

Single-crystal X-ray diffraction analysis reveals that $\mathbf{1}$ crystallizes in the triclinic space group $P \overline{1}$ (No. 2), and consists of one $\mathrm{V}_{10} \mathrm{O}_{28}$ cluster, one $\mathrm{Zn}(\mathrm{bte})\left(\mathrm{H}_{2} \mathrm{O}\right)_{4}$ moiety, one $\mathrm{Zn}_{2}$ (bte) $\left(\mathrm{H}_{2} \mathrm{O}\right)_{10}$ moiety and eight water molecules, as shown in Fig. 1. The $\mathrm{V}_{10} \mathrm{O}_{28}$ cluster consists of ten edge-sharing [ $\mathrm{VO}_{6}$ ] octahedra and exhibits a ball shape structure, similar to the decavanadate structure reported in the literature [33]. There are two crystallographically independent $\mathrm{Zn}$ ions in $\mathbf{1}$, and $\mathrm{Zn} 1$ is hexa-coordinated in a distorted octahedral geometry achieved by two nitrogen atoms from two bte ligand molecules and four oxygen atoms from four water molecules (Fig. $\mathrm{S} 1) . \mathrm{Zn} 2$ is also hexa-coordinated in an octahedral geometry, defined by one nitrogen 
atom from one bte molecule and five oxygen atoms from five water molecules. The bond lengths around the $\mathrm{Zn}$ atoms are in the range of 2.062(6)-2.141(7) $\AA$ ( $\mathrm{Zn}-\mathrm{O})$ and $2.098(6)-2.132(7) \AA(\mathrm{Zn}-\mathrm{N})$; the bond angles are in the range of $84.3(3)-180.000(1)^{\circ}$ $(\mathrm{O}-\mathrm{Zn}-\mathrm{O}), 88.2(2)-172.5(3)^{\circ}(\mathrm{N}-\mathrm{Zn}-\mathrm{O})$ and $180.000(1)^{\circ}(\mathrm{N}-\mathrm{Zn}-\mathrm{N})$.

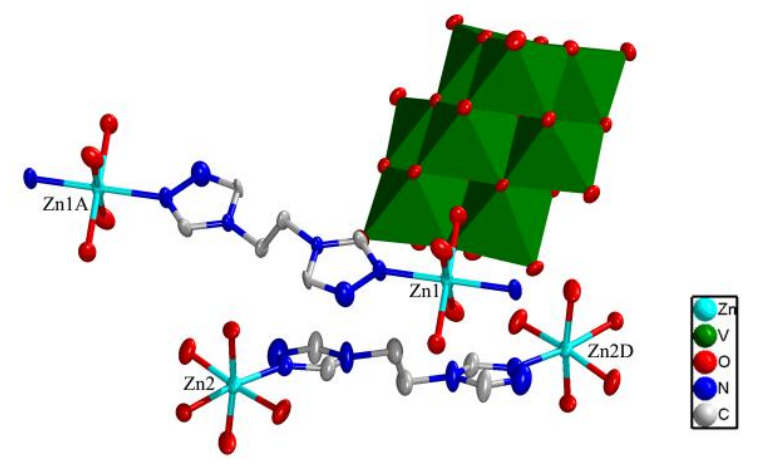

Fig. 1 A view of the basic building blocks in 1 (The $\mathrm{H}$ atoms of coordinated water molecules and free water molecules are omitted for clarity, symmetry codes of A and D are presented in Fig. S1).

Compound $\mathbf{1}$ is a supramolecular layer structure, which can be described as follows: firstly, the bte ligands are connected to each other by sharing $\mathrm{Zn}$ ions to form an infinite $\mathrm{Zn}$-bte metal-organic cation wave-like chain. Then the $\mathrm{V}_{10} \mathrm{O}_{28}$ clusters are located between two neighboring Zn-bte chains (Fig. 2a), and link two chains through

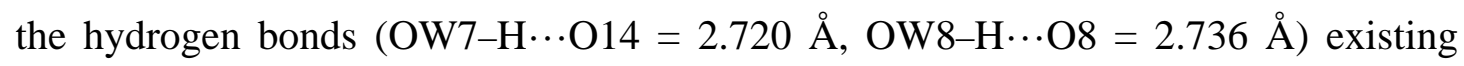
between the oxygen atoms of the $\mathrm{V}_{10} \mathrm{O}_{28}$ clusters and the hydrogen atoms of the coordination water molecules, to achieve $\mathrm{V}_{10} \mathrm{O}_{28}$-based $1 \mathrm{D}$ rail-like chains (Fig. 2b), which the $\mathrm{V}_{10} \mathrm{O}_{28}$ clusters act as the "railroad ties" and the $\mathrm{Zn}$-bte chains act as the "rails". Furthermore, the adjacent rail-like chains are interconnected by sharing the rail chains to generate a two-dimensional (2D) supramolecular layer, as shown in Fig. 
2c.

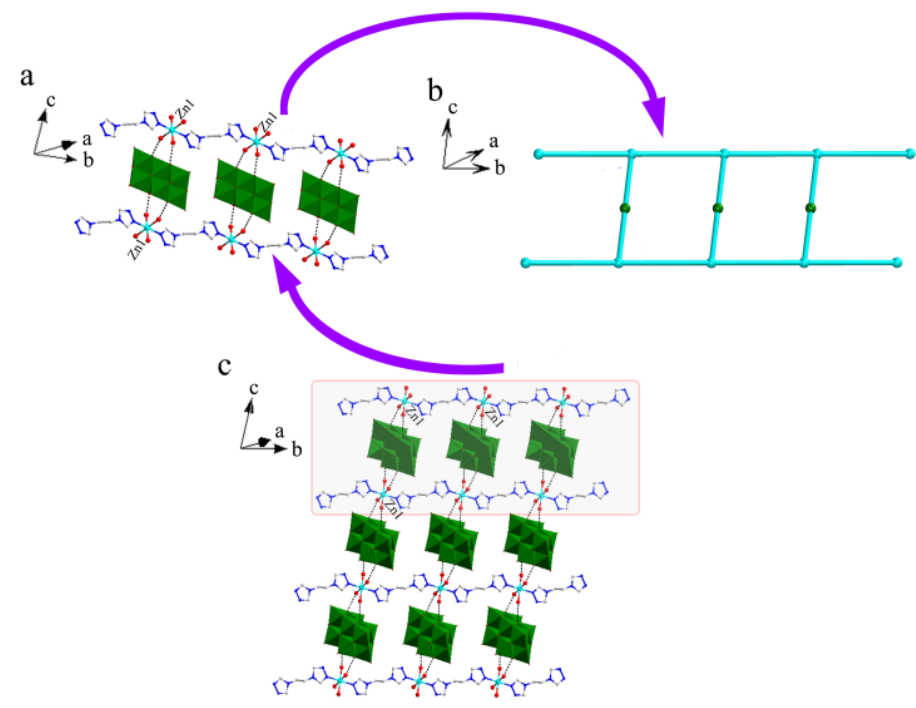

Fig. 2 (a, b) View of "rail-like" Zn-bte chains modified POMs; (c) The 2D supramolecular structure in $\mathbf{1}$.

\subsection{2. $\left[\mathrm{Zn}_{2}(b t p)_{4}\left(\mathrm{H}_{2} \mathrm{O}\right)_{6}\right]\left(\mathrm{H}_{2} \mathrm{~V}_{10} \mathrm{O}_{28}\right) \cdot 4 \mathrm{H}_{2} \mathrm{O}(2)$}

Single-crystal X-ray diffraction analysis reveals that $\mathbf{2}$ crystallizes in the triclinic space group $P^{\overline{1}}$ (No. 2), and 2 is composed of one $\mathrm{H}_{2} \mathrm{~V}_{10} \mathrm{O}_{28}$ polyoxoanion, one $\left[\mathrm{Zn}_{2}(\mathrm{btp})_{4}\left(\mathrm{H}_{2} \mathrm{O}\right)_{6}\right]$ moiety (btp = 1,3-bis(1,2,4-triazol-1-y1)propane) and four water molecules, as shown in Fig. 3. There are two crystallographically independent $\mathrm{Zn}$ cations, and $\mathrm{Zn} 1$ is hexa-coordinated in an octahedral geometry achieved by four nitrogen atoms from four btp ligands and two oxygen atoms from two water molecules (Fig. S2). The Zn2 atom adopts an elongated octahedral coordination geometry established by two nitrogen donors of two btp ligands and four oxygen atoms of four different water molecules. The bond lengths around the $\mathrm{Zn}$ atoms are in the range of 2.096(3)-2.209(3) $\AA(\mathrm{Zn}-\mathrm{O})$ and 2.049(3)-2.183(4) $\AA(\mathrm{Zn}-\mathrm{N})$; the bond angles are in the range of $89.13(12)-180.000(1)^{\circ}(\mathrm{O}-\mathrm{Zn}-\mathrm{O}), 87.70(14)-92.30(14)^{\circ}$ $(\mathrm{N}-\mathrm{Zn}-\mathrm{O})$ and $88.00(14)-180.000(1)^{\circ}(\mathrm{N}-\mathrm{Zn}-\mathrm{N})$. 


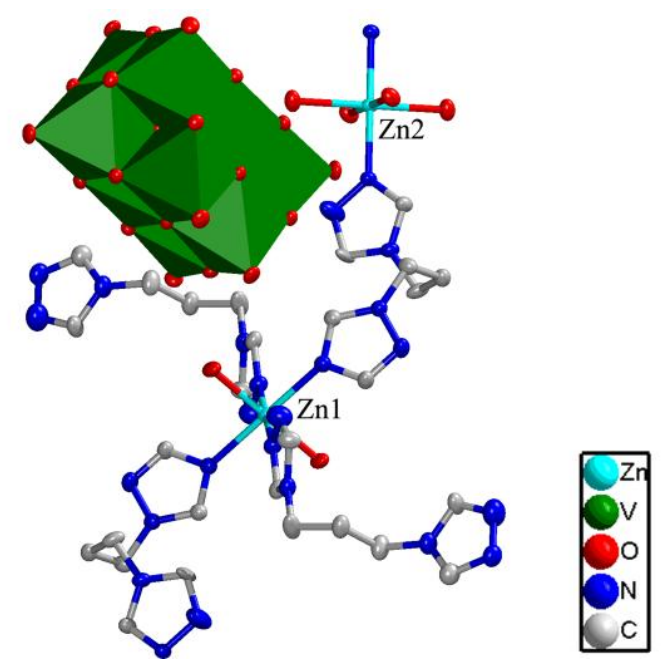

Fig. 3 A view of the basic building blocks in 2 (The $\mathrm{H}$ atoms of coordinated water molecules and free water molecules are omitted for clarity).

Compound 2 shows a two dimensional grid sheet. Such structure can be described in detail as follows: on the one hand, four btp ligands are alternately linked by the Zn1 center to form a "pinwheel" striped structure (Fig. S3). On the other hand, the $\mathrm{Zn} 2$ atom acts as a connector covalently bonding to adjacent two pinwheel striped complexes, resulting in an interesting $\left[\mathrm{Zn}_{2}(\mathrm{btp})_{4}\left(\mathrm{H}_{2} \mathrm{O}\right)_{6}\right]^{4+}$ infinite chain (Fig 4a). Furthermore, the $\mathrm{H}_{2} \mathrm{~V}_{10} \mathrm{O}_{28}$ clusters are connected by $\left[\mathrm{Zn}_{2}(\mathrm{btp})_{4}\left(\mathrm{H}_{2} \mathrm{O}\right)_{6}\right]^{4+}$ infinite chains through $\mathrm{O}-\mathrm{H} \cdots \mathrm{O}$ hydrogen bonds $(\mathrm{OW} 8-\mathrm{H} \cdots \mathrm{O} 12=2.880 \AA$ A, $\mathrm{OW} 1-\mathrm{H} \cdots \mathrm{OW} 2$ $=2.834 \AA$ ) to form a 2D network (Fig 4b). The $2 \mathrm{D}$ network is a grid sheet with effective rectangular windows $\left(\mathrm{Zn}^{\mathrm{II}} 1\right.$ ions as the corners, btp- $\mathrm{Zn}{ }^{\mathrm{II}} 2$-btp subunits as the long edges and the $\left[\mathrm{H}_{2} \mathrm{~V}_{10} \mathrm{O}_{28}\right]^{4-}$ molecules as the short edges) and the size of each window is ca. $19.71 \times 15.73 \AA^{2}$, as shown in Fig. 4c. 


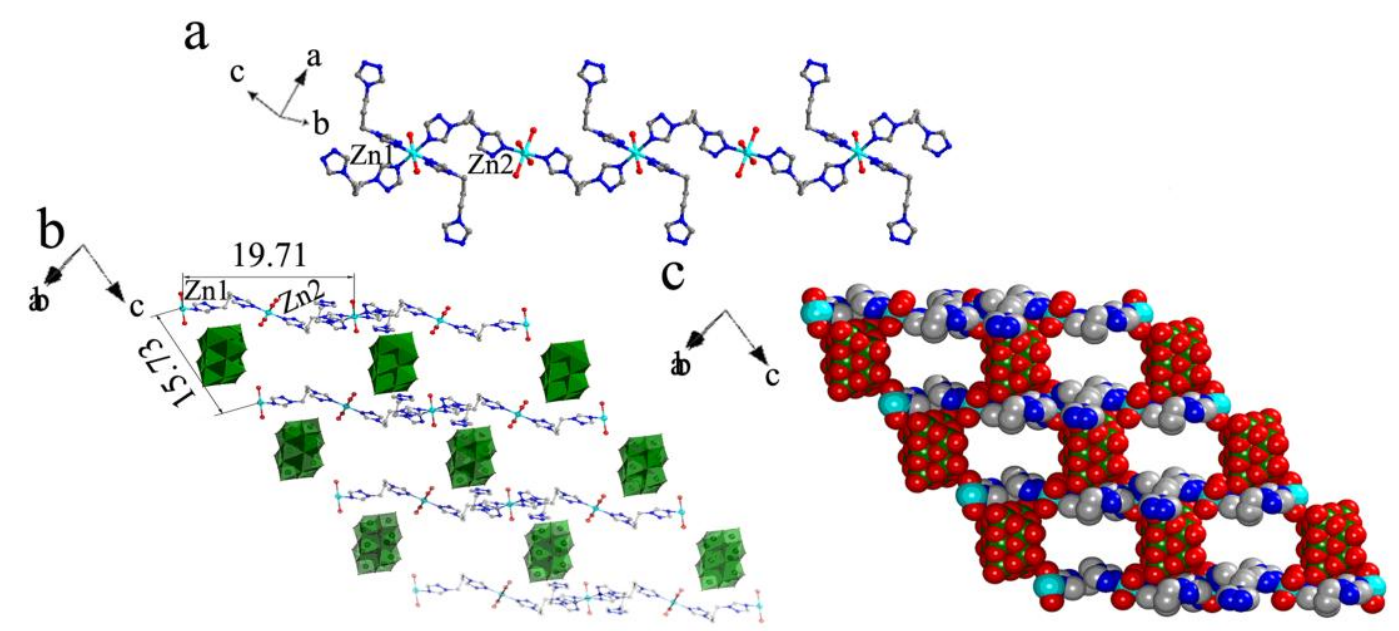

Fig. 4 (a) View of the infinite 1D chain; (b, c) The 2D grid sheet. All the hydrogen atoms are omitted for clarity.

\subsection{3. $\left[\mathrm{Zn}\left(\mathrm{H}_{2} \mathrm{O}\right)_{6}\right]\left[\mathrm{Zn}_{2}(b t b)_{2} \mathrm{~V}_{10} \mathrm{O}_{28}\left(\mathrm{H}_{2} \mathrm{O}\right)_{6}\right] \cdot 4 \mathrm{H}_{2} \mathrm{O}$ (3)}

Single-crystal X-ray diffraction analysis reveals that $\mathbf{3}$ crystallizes in the triclinic space group $P \overline{1}$ (No. 2), and consists of three $\mathrm{Zn}$ ions, two btb ligands (btb = 1,4-bis(1,2,4-triazol-1-yl)butane), one $\mathrm{V}_{10} \mathrm{O}_{28}$ cluster, twelve coordinated water molecules and four free water molecules, as shown in Fig. 5. There are two crystallographically independent $\mathrm{Zn}$ ions in $\mathbf{3}$, and the $\mathrm{Zn} 1$ cation adopts "seesaw" geometry achieved by two nitrogen atoms from two btb ligands and one oxygen atom from one $\mathrm{V}_{10} \mathrm{O}_{28}$ cluster and three oxygen atoms from three water molecules. Thus the $\mathrm{Zn}^{2+}$ is in an octahedral geometry (Fig. S4). $\mathrm{Zn} 2$ is also hexa-coordinated in an octahedral geometry, defined by six oxygen atoms from six water molecules. The bond lengths around the $\mathrm{Zn}$ atoms are in the range of 2.067(4)-2.222(3) $\AA$ ( $\mathrm{Zn}-\mathrm{O})$ and $2.069(4)-2.086(4) \AA \quad(\mathrm{Zn}-\mathrm{N})$; the bond angles are in the range of 86.43(13)-180.000(2) $(\mathrm{O}-\mathrm{Zn}-\mathrm{O}), 83.89(14)-97.27(16)^{\circ}(\mathrm{N}-\mathrm{Zn}-\mathrm{O})$ and $168.54(16)^{\circ}$ 
$(\mathrm{N}-\mathrm{Zn}-\mathrm{N})$.

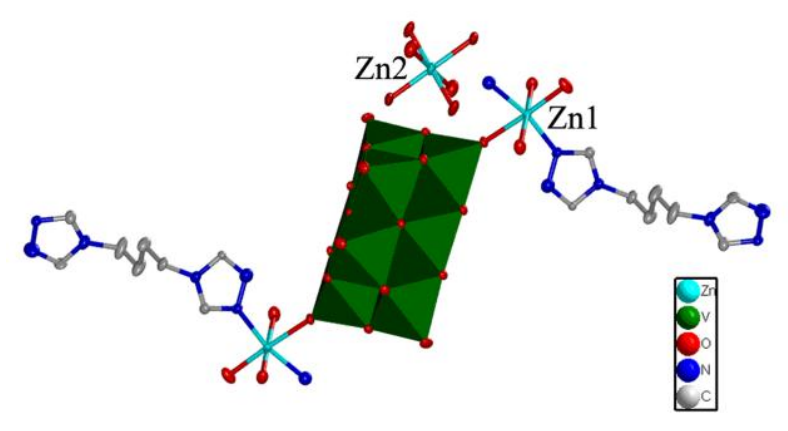

Fig. 5 A view of the basic building blocks in 3 (The $\mathrm{H}$ atoms of coordinated water molecules and free water molecules are omitted for clarity).

The structural feature of $\mathbf{3}$ is a supramolecular layer structure, which can be described as follows: on the one hand, each btb molecule (btb = 1,4-bis(1,2,4-triazol-1-yl)ethane) links two symmetrical Zn1 ions into an twisty $[\mathrm{Zn}(\mathrm{btp})]^{2+}{ }_{\mathrm{n}}$ polymeric chain. On the other hand, each $\mathrm{V}_{10} \mathrm{O}_{28}$ cluster provides two bridge oxygen atoms $(\mathrm{O} 10$ and $\mathrm{O} 10 \mathrm{~B})$ of a pair of opposite $\left[\mathrm{VO}_{6}\right]$ octahedra and coordinates with two symmetrical $\mathrm{Zn} 1$ atoms, as shown in Fig. 6a. So the $\mathrm{V}_{10} \mathrm{O}_{28}$ clusters fuse two neighboring $[\mathrm{Zn}(\mathrm{btp})]^{2+}{ }_{\mathrm{n}}$ chains together, resulting in $1 \mathrm{D}$ ladder-like chains. The $\mathrm{V}_{10} \mathrm{O}_{28}$ clusters act as the "rungs", as shown in Fig. 6b. Furthermore, these $1 \mathrm{D}$ chains are linked together via weak interactions $(\mathrm{OW} 8-\mathrm{H} \cdots \mathrm{O} 14=2.698 \AA$, OW9-H $\cdots \mathrm{O} 8=2.765 \AA$ ) ) to form a 2D supramolecular structure, as shown in Fig. 6c. Noticeably, there are big voids in compound 3 . The void showing a tetranuclear cycle structural motif with a dimension of $c a .14 .18 \times 12.29 \AA^{2}$ is formed by two btp ligands, two $\mathrm{V}_{10} \mathrm{O}_{28}$ clusters and four $\mathrm{Zn}^{\mathrm{II}}$ ion linkages (Fig. 6d). 


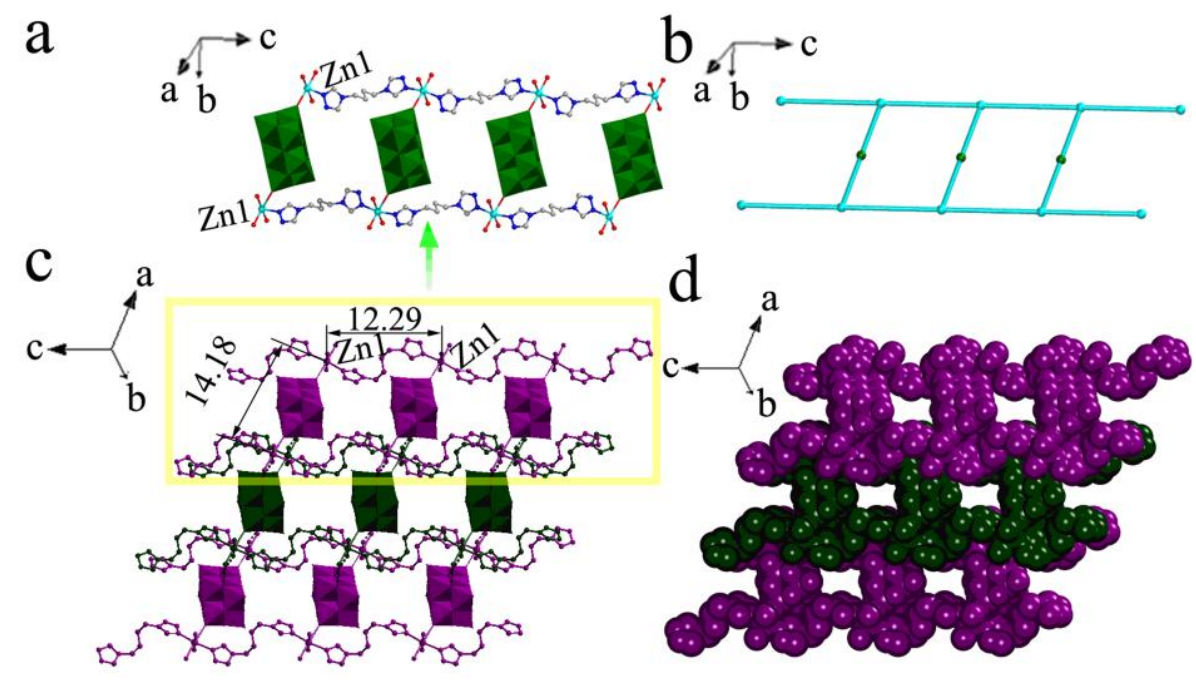

Fig. $6(\mathbf{a}, \mathbf{b})$ View of "ladder-like" chain; $(\mathbf{c}, \mathbf{d})$ The 2D supramolecular structure in 3. All the hydrogen atoms are omitted for clarity.

\subsection{4. $\left[\mathrm{Zn}_{2}(b t h)\left(\mathrm{H}_{2} \mathrm{O}\right)_{10}\right]\left(\mathrm{H}_{2} \mathrm{~V}_{10} \mathrm{O}_{28}\right) \cdot 6 \mathrm{H}_{2} \mathrm{O}(4)$}

Single-crystal X-ray diffraction analysis reveals that $\mathbf{4}$ crystallizes in the triclinic space group $P \overline{1}$ (No. 2), and consists of two $\mathrm{Zn}$ ions, one bth ligand (bth = 1,6-bis(1,2,4-triazol-1-yl)hexane), one $\mathrm{H}_{2} \mathrm{~V}_{10} \mathrm{O}_{28}$ cluster, ten coordinated water molecules and six free water molecules, as shown in Fig. 7. One crystallographically unique $\mathrm{Zn}^{\mathrm{II}}$ ion exhibits an octahedral configuration that is coordinated by one nitrogen atom (N1) from the triazole ring of one bth ligand, five oxygen atoms (OW1, OW2, OW3, OW4, OW5) from five different water molecules (Fig. S5). The bond lengths around the $\mathrm{Zn}$ atoms are around 2.093(5)-2.158(5) $\AA$ for $\mathrm{Zn}-\mathrm{O}$ and 2.097(5) $\AA$ for $\mathrm{Zn}-\mathrm{N}$. The bond angles are in the range of $86.09(19)-178.4(2)^{\circ}(\mathrm{O}-\mathrm{Zn}-\mathrm{O})$, $88.0(2)-173.6(2)^{\circ}(\mathrm{N}-\mathrm{Zn}-\mathrm{O})$. 


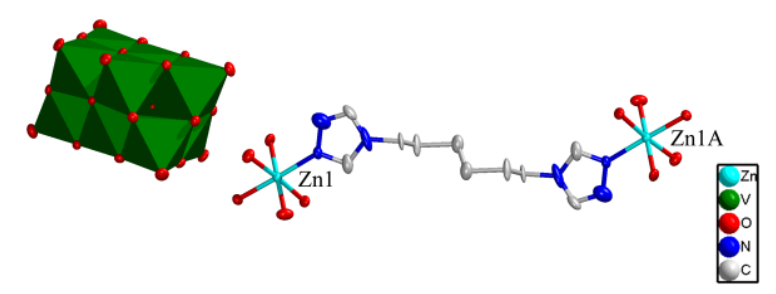

Fig. 7 A view of the basic building blocks in 4 (The $\mathrm{H}$ atoms of coordinated water molecules and free water molecules are omitted for clarity, symmetry code of $\mathrm{A}$ is presented in Fig. S5).

Compound $\mathbf{4}$ is a supramolecular 2D layer, which can be described as follows: on the one hand, each bth molecule (bth $=1,6$-bis(1,2,4-triazol-1-yl) hexane) links two symmetrical $\mathrm{Zn} 1$ ions into a $\left[\mathrm{Zn}_{2}(\mathrm{bth})\left(\mathrm{H}_{2} \mathrm{O}\right)_{10}\right]^{4+}$ coordinated unit. On the other hand, each $\mathrm{H}_{2} \mathrm{~V}_{10} \mathrm{O}_{28}$ cluster is connected to two adjacent $\left[\mathrm{Zn}_{2}(\text { bth })\left(\mathrm{H}_{2} \mathrm{O}\right)_{10}\right]^{4+}$ units via intermolecular hydrogen bondings (OW1-H $\cdots \mathrm{O} 5=2.867 \AA$, OW3-H $\cdots \mathrm{O} 6=2.745 \AA$,

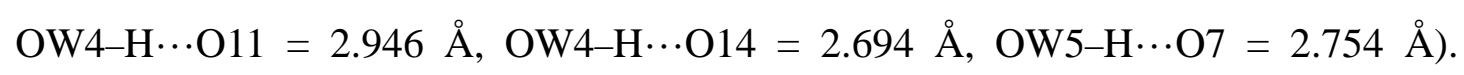
Consequently, $\left[\mathrm{Zn}_{2}(\right.$ bth $\left.)\left(\mathrm{H}_{2} \mathrm{O}\right)_{10}\right]\left(\mathrm{H}_{2} \mathrm{~V}_{10} \mathrm{O}_{28}\right)$ structure fragments are formed. Further, the $\left[\mathrm{Zn}_{2}(\mathrm{bth})\left(\mathrm{H}_{2} \mathrm{O}\right)_{10}\right]\left(\mathrm{H}_{2} \mathrm{~V}_{10} \mathrm{O}_{28}\right)$ fragments are connected to each other to achieve a 1D chain, as shown in Fig. 8a. There exist hydrogen bonding interactions between the oxygen atoms of the $\mathrm{H}_{2} \mathrm{~V}_{10} \mathrm{O}_{28}$ clusters and the hydrogen atoms of the water molecules from neighboring $\mathrm{Zn}_{2}(\mathrm{bth})\left(\mathrm{H}_{2} \mathrm{O}\right)_{10}$ fragments, which stabilize the whole structure of 4. Consequently, a 2D supramolecular layer is formed (Fig. 8b).

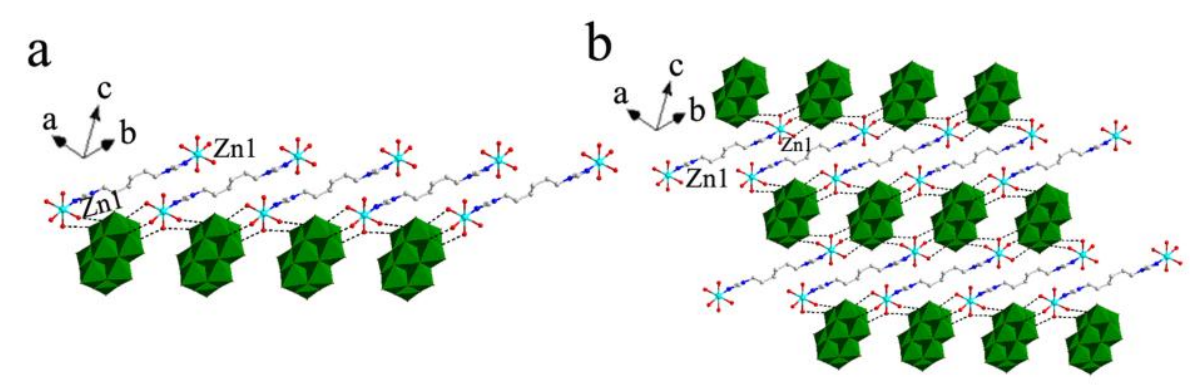

Fig. 8 (a) The supramolecular chain; (b) The supramolecular 2D layer in 4. 
3.1.5. Influence of the spacer length of the flexible bis(triazole) ligands on the structures of the title compounds

Compounds 1-4 were synthesized under the same conditions, except for using four flexible bis(triazole) ligands with different spacer length. By comparing compounds 1 to $\mathbf{4}$, we found that a minor change of the ligands greatly influences the structures of metal organic motifs and final architectures, although these compounds are built upon the same $\mathrm{V}_{10} \mathrm{O}_{28}$ anions and the same $\mathrm{Zn}^{\mathrm{II}}$ ions with similar coordination geometries. In compound $\mathbf{1}$, the metal-organic motif is a $1 \mathrm{D}$ wave-like chain which is constructed by $\mathrm{Zn}^{\mathrm{II}}$ ions and bte ligands. The short $-\left(\mathrm{CH}_{2}\right)_{2}-$ spacer makes the bte molecule act as a bidentate ligand to coordinate to two $\mathrm{Zn}$ centers by using two terminal $\mathrm{N}$ donors, which plays an extension role acting as a bridging ligand. Then the metal-organic motifs are linked by $\mathrm{V}_{10} \mathrm{O}_{28}$ clusters to form $1 \mathrm{D}$ rail-like chains and finally generate a $2 \mathrm{D}$ supermolecular network. Similarly, in compound 2, the $\mathrm{Zn}{ }^{\mathrm{II}}$-btp metal-organic motif is also a $1 \mathrm{D}$ chain. But, in the chain, the half amount of the btp ligands is one-connected acting as hanging pendants, and thus "pinwheel" striped structures are formed. Furthermore, the neighboring chains are further fused by the $\mathrm{H}_{2} \mathrm{~V}_{10} \mathrm{O}_{28}$ anions to construct a grid sheet. In compound $\mathbf{3}$, the metal-organic motif is a twisty chain which is constructed by $\mathrm{Zn}^{\mathrm{II}}$ ions and bidentate btb ligands, and the $\mathrm{V}_{10} \mathrm{O}_{28}$ clusters act as connectors covalently bonding to $\mathrm{Zn}$ ions of adjacent metal-organic chains, resulting in 1D ladder-like chains. In compound $\mathbf{4}$, the bth molecule possesses the longest spacer $-\left(\mathrm{CH}_{2}\right)_{6}$ - with a big space hindrance. And thus the $\mathrm{Zn}$-bth metal-organic motif is a discrete fragment. Finally, the discrete 
$\mathrm{Zn}$-bth fragments are connected by $\mathrm{H}_{2} \mathrm{~V}_{10} \mathrm{O}_{28}$ clusters via intermolecular hydrogen bondings to form a supramolecular layer.

\subsection{Analyses of BVS, IR measurements}

Bond valence sum calculations: In order to confirm the valence of the metal centers in 1-4, bond valence sum (BVS) calculations were carried out using the method of I. D. Brown [62]. The BVS calculations show that the oxidation states of V and $\mathrm{Zn}$ atoms in $\mathbf{1}$ to $\mathbf{4}$ are +5 and +2 , respectively (Table S2-S5). Considering the charge neutrality requirement and the most rational distribution of charges in the solid-state structures of $\mathbf{2}$ and $\mathbf{4}$, we assume the presence of two protons attached to the POMs in compounds $\mathbf{2}$ and $\mathbf{4}$ for charge balance, as also observed in $\left[\mathrm{Ag}_{2}(3 \mathrm{atrz})_{2}\right]_{2}\left[\left(\mathrm{HPMo}^{\mathrm{VI}}{ }_{10} \mathrm{Mo}_{2}{ }_{2} \mathrm{O}_{40}\right)[59]\right.$

IR spectra. In the IR spectra of compounds 1-4, the characteristic peaks at 960, $849,804,736,587,461 \mathrm{~cm}^{-1}$ in $1,956,837,747,670,600,447 \mathrm{~cm}^{-1}$ in $2,953,851$, $749,670,558,453 \mathrm{~cm}^{-1}$ in $\mathbf{3}$ as well as $962,845,806,748,592,547,461 \mathrm{~cm}^{-1}$ in $\mathbf{4}$, are respectively attributed to the $v(\mathrm{~V}=\mathrm{O}), v_{a s}(\mathrm{~V}-\mathrm{O}-\mathrm{M})(\mathrm{M}=\mathrm{V}$ or $\mathrm{Zn})$ vibrations [33,63] (Fig. S6). In contrast to the IR spectra of compounds $\mathbf{1}-\mathbf{4}$ and parent $\mathrm{V}_{10} \mathrm{O}_{28}$ polyoxoanion [33], it can be observed that the shape of peaks in the range 600-1000 $\mathrm{cm}^{-1}$ is similar to that of $\mathrm{V}_{10} \mathrm{O}_{28}$ except slight shifts of some peaks due to the interactions between the polyanions and the $\mathrm{Zn}^{2+}$ cations in the solid state, which indicates that the polyanions in compounds $\mathbf{1}-\mathbf{4}$ still retain the basic $\mathrm{V}_{10} \mathrm{O}_{28}$ structure. This is in agreement with the results of single-crystal X-ray diffraction analyses. Additionally, the characteristic bands at $1042-1637 \mathrm{~cm}^{-1}$ in $\mathbf{1}-\mathbf{4}$ can be regarded as 
features of the bte, btp, btb, or bth molecules [25, 64]. The broad peaks at ca. 3440 $\mathrm{cm}^{-1}$ in 1-4 are ascribed to characteristic peaks of the water molecule $\mathrm{O}-\mathrm{H}$ stretches.

\subsection{Cyclic Valtammetry $(C V)$}

The polyoxovanadates have attracted much interest in electrochemical and electrocatalysis fields because of their ability to undergo reversible mono-electron redox processes $\mathrm{V}^{\mathrm{V}} / \mathrm{V}^{\mathrm{IV}}[33,65,66]$. Especially, vanadium oxides are of particular interest as candidates for active cathode materials in reversible lithium batteries or electrochemical devices [33]. In order to study the electrochemical behaviors of $\mathbf{1 - 4}$, the four compounds were used as solid modifiers to fabricate three-dimensional bulk-modified carbon paste electrodes (CPEs) by direct mixing method due to their insolubility. The CPEs were prepared according to the previous method [66].

\subsubsection{Voltammetric behaviors of compounds modified carbon paste electrodes}

The electrochemical behaviors of the 1-, 2-, 3- and 4-CPEs are similar except for some slight potential shifts. Thus, the 3-CPE and 4-CPE cases have been taken as examples to study their electrochemical properties. The cyclic voltammograms for 3and 4-CPEs in $1 \mathrm{M} \mathrm{H}_{2} \mathrm{SO}_{4}$ solution at different scan rates are presented in Fig. 9. In the potential range of $1.6 \mathrm{~V}$ to $-0.2 \mathrm{~V}$ for 3-CPE and 4-CPE, a pair of quasi-reversible redox peaks I-I' are observed, with the half-wave potentials $E_{1 / 2}$ at $+0.899 \mathrm{~V}$ for 3-CPE and +0.893 $\mathrm{V}$ for 4-CPE (scan rate: $80 \mathrm{mV} \mathrm{s}^{-1}$ ), respectively. The redox peak I-I' should be correspond to one-electron quasi-reversible redox processes of vanadium atoms $\left(\mathrm{V}^{\mathrm{V}} / \mathrm{V}^{\mathrm{IV}}\right)$ [33]. The values of $\mathrm{E}_{1 / 2}$ for 3-CPE and 4-CPE are close. The small difference between $\mathrm{E}_{1 / 2}$ for 3-CPE and 4-CPE suggests the core $\mathrm{V}_{10} \mathrm{O}_{28}$ is 
the active centre for electrochemical redox activity in both CPEs, whereas the corresponding complex fragments have only a slight effect on the electrochemical behaviours of 3-CPE or 4-CPE.

a

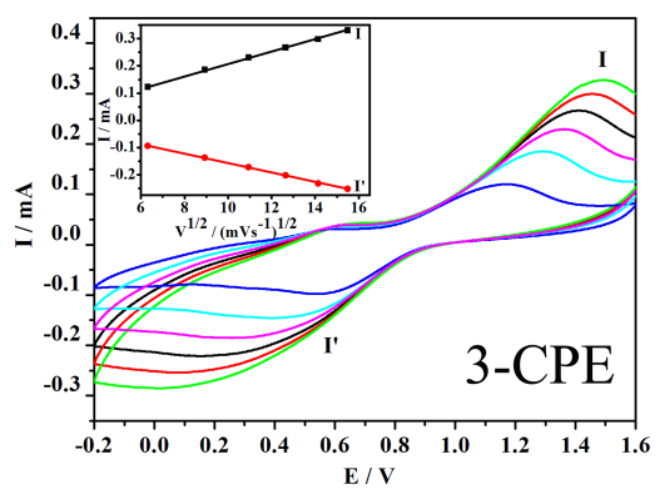

$\mathrm{b}$

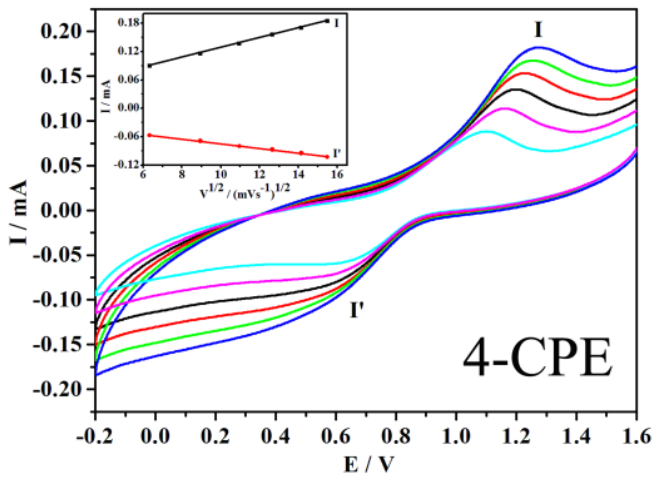

Fig. 9 Cyclic voltammograms for (a) 3-CPE and (b) 4-CPE in $1 \mathrm{M} \mathrm{H}_{2} \mathrm{SO}_{4}$ solution at different scan rates (from inner to outer): $0.04,0.08,0.12,0.16,0.20,0.24 \mathrm{~V} \mathrm{~s}^{-1}$. The insets show a linear dependence of the anodic and the cathodic peak currents of I-I' with square root of the scan rates.

As shown in Fig. 9, when the scan rates were varied from 0.04 to $0.24 \mathrm{~V} \cdot \mathrm{s}^{-1}$ for 3- and 4-CPEs, the peak potentials change gradually: the cathodic peak potentials shift towards the negative direction and the corresponding anodic peak potentials shift towards the positive direction with increasing scan rates. Furthermore, up to $240 \mathrm{mV}$ $\mathrm{s}^{-1}$ the peak currents for 3 - and 4-CPEs are proportional to the square root of the scan rates, as shown in the insert of Fig. 9, which indicates that the redox processes are diffusion-controlled [67].

\subsubsection{Electrocatalytic activities of compound-CPEs}

The electrocatalytic properties of 3- and 4-CPEs have been also investigated. Fig. 
10 shows the electrocatalytic oxidation of nitrite by 3 - and 4-CPEs in $1 \mathrm{M} \mathrm{H}_{2} \mathrm{SO}_{4}$ solution. It can be clearly noted that with addtion of nitrite gradually, the anodic peak currents of $\mathrm{V}(\mathrm{IV})$ wave of 3- and 4-CPEs substantially increases obviously, suggesting that the 3- and 4-CPEs show electrocatalytic activities towards the oxidation of $\mathrm{NO}_{2}^{-}$. The insets of Fig. 10a and b show the relationship between the anodic currents and concentrations of $\mathrm{NO}_{2}^{-}$. Furthermore, the electrocatalytic efficiency (CAT) of 3-CPE and 4-CPE can be roughly calculated by using CAT formula [68]. The results show that the CAT values towards the oxidation of $\mathrm{NO}_{2}{ }^{-}$are ca. $39.8 \%$ and $65.1 \%$, respectively, which suggests that $\mathbf{3}$ and $\mathbf{4}$ have potential applications in detection of $\mathrm{NO}_{2}^{-}$.

a

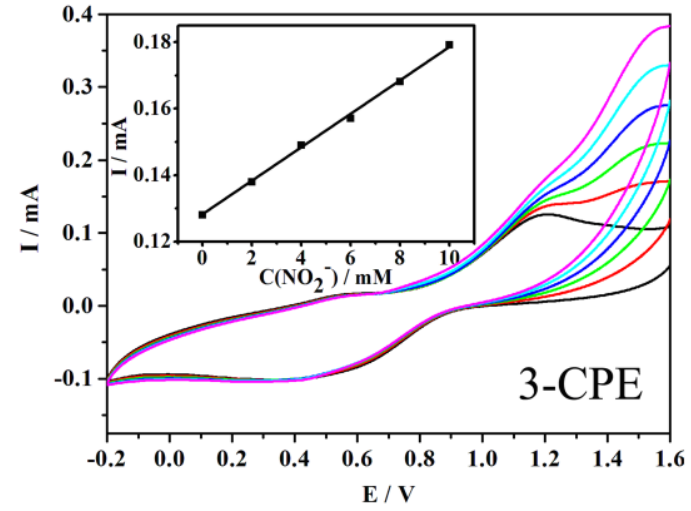

b

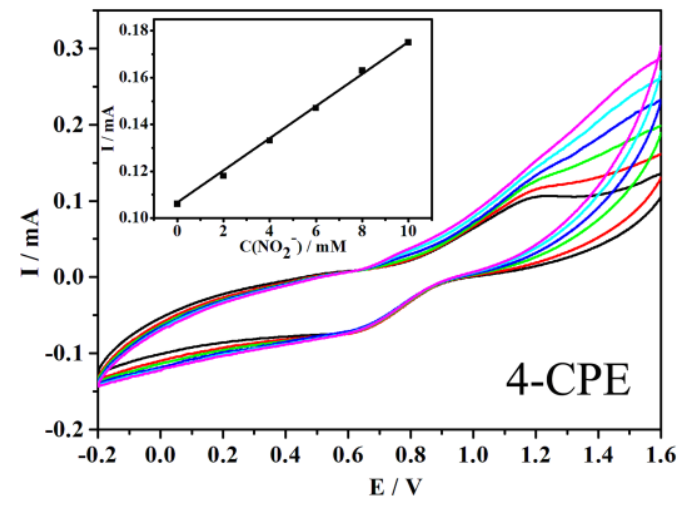

Fig. 10 Oxidation of $\mathrm{NO}_{2}^{-}$for (a) 3-CPE and (b) 4-CPE in $1 \mathrm{M} \mathrm{H}_{2} \mathrm{SO}_{4}$ solution containing $\mathrm{NO}_{2}^{-}$in various concentrations (from inner to outer): 0, 2, 4, 6, 8, $10 \mathrm{mM}$. Scan rate: $80 \mathrm{mV} / \mathrm{s}$. Potentials vs $\mathrm{Ag} / \mathrm{AgCl}$. The insets show a linear dependence of the anodic catalytic currents of wave I with $\mathrm{NO}_{2}^{-}$concentrations.

Further, the stability experiments for 3-CPE and 4-CPE have been investigated by cyclic voltammetry scanning for 60 cycles in $1 \mathrm{M} \mathrm{H}_{2} \mathrm{SO}_{4}$ solution. As shown in Fig. 
S8, it can be seen that the electrodes exhibit almost no loss in the current signal after 60 cycles, which suggests that the catalysts of 3-CPE and 4-CPE have high stability.

\section{Conclusions}

In summary, four new inorganic-organic hybrid compounds based on $\mathrm{V}_{10} \mathrm{O}_{28}$ anions and Zn-bis(triazole) complexes have been synthesized via a simple conventional method and structurally characterized. The successful isolation of these compounds not only provides four examples of $\mathrm{V}_{10} \mathrm{O}_{28}$-based supramolecular compounds but also confirms that tuning the spacer length of organic ligands is an effective strategy to obtain POM-based hybrids with intriguing structures. Furthermore, the results of electrochemical properties indicate that these compounds have electrocatalytic activities towards oxidation of nitrite molecules. The successful syntheses of these compounds will inspire us in expanding our work to exploit high-dimensional frameworks based on the $\mathrm{V}_{10} \mathrm{O}_{28}$ clusters via the introduction of other kinds of metal cations and organonitrogen ligands. Further work for preparing novel $\mathrm{V}_{10} \mathrm{O}_{28}$-based hybrids constructed from other flexible ligands is in progress.

\section{Acknowledgments.}

This work was financially supported by the NSF of China (21371041, 51572063, and 51102059), the science and technology innovation foundation of Harbin (2014RFXXJ076), and the SF for the Young Innovative Talents of HUST (No.201307). 


\section{References}

[1] J.C. Jiang, O.M. Yaghi, Chem. Rev. 115 (2015) 6966-6997.

[2] J.L.C. Rowsell, O.M. Yaghi, Angew. Chem. Int. Ed. 44 (2005) 4670-4679.

[3] M. Fujita, Y.J. Kwon, S. Washizu, K. Ogura, J. Am. Chem. Soc. 116 (1994) $1151-1152$.

[4] K. Sumida, N. Moitra, J Reboul, S. Fukumoto, K. Nakanishi, K. Kanamori, S. Furukawa, S. Kitagawa, Chem. Sci. 6 (2015) 5938-5946.

[5] W.W. Xiong, G.D. Zhang, Q.C. Zhang, Inorg. Chem. Front. 1 (2014) 292-301.

[6] J.K. Gao, K.Q. Ye, L. Yang, W.W. Xiong, L. Ye, Y. Wang, Q.C. Zhang, Inorg. Chem. 53 (2014) 691-693.

[7] H.S. Lu, L.L. Bai, W.W. Xiong, P.Z. Li, J.F. Ding, G.D. Zhang, T. Wu, Y.L. Zhao, J.M. Lee, Y.H. Yang, B.Y. Geng, Q.C. Zhang, Inorg. Chem. 53 (2014) $8529-8537$.

[8] W.W. Xiong, P.Z. Li, T.H. Zhou, A.I.Y. Tok, R. Xu, Y.L. Zhao, Q.C. Zhang, Inorg. Chem. 52 (2013) 4148-4150.

[9] W.W. Xiong, E.U. Athresh, Y.T. Ng, J.F. Ding, T. Wu, Q.C. Zhang, J. Am. Chem. Soc. 135 (2013) 1256-1259.

[10] J.K. Gao, K.Q. Ye, M. He, W.W. Xiong, W.F. Cao, Z.Y. Lee, Y. Wang, T. Wu, F. W. Huo, X.G. Liu, Q.C. Zhang, J. Solid State Chem. 206 (2013) 27-31.

[11] W.W. Xiong, J.W. Miao, K.Q. Ye, Y. Wang, B. Liu, Q.C. Zhang, Angew. Chem. Int. Ed. 54 (2015) 546-550.

[12] W.W. Xiong, Q.C. Zhang, Angew. Chem. Int. Ed. 54 (2015) 11616-11623. 
[13] M.T. Pope, A. Müller, Eds. Polyoxometalate Chemistry from Topology via Self-Assembly to Applications, Kluwer Academic Publishers: Dordrecht. 2001.

[14] A. Dolbecq, E. Dumas, C.R. Mayer, P. Mialane, Chem. Rev. 110 (2010) 6009-6048.

[15] D.Y. Du, L.K. Yan, Z.M. Su, S.L. Li, Y.Q. Lan, E.B. Wang, Coord. Chem. Rev. 257 (2013) 702-717.

[16] D.L. Long, R. Tsunashima, L. Cronin, Angew. Chem. Int. Ed. 49 (2010) $1736-1758$.

[17] C.Y. Sun, S.X. Liu, D.D. Liang, K.Z. Shao, Y.H. Ren, Z.M. Su, J. Am. Chem. Soc. 131 (2009) 1883-1888.

[18] S. Nakamura, T. Ozeki, J. Chem. Soc. Dalton Trans. (2001) 472-480.

[19] J.Q. Sha, J.W. Sun, M.T. Li, C. Wang, G.M. Li, P.F. Yan, L.J. Sun, Dalton Trans. 42 (2013) 1667-1677.

[20] H.N. Miras, L.V. Nadal, L.Cronin, Chem. Soc. Rev. 43 (2014) 5679-5699.

[21] J. Yang, K.L. Huang, Z.F. Pu, Y. Gong, H. Li, C.W. Hu, J. Mol. Struct. 789 (2006) $162-168$.

[22] X.L. Wang, C. Xu, H.Y. Lin, G.C. Liu, S. Yang, Q. Gao, A.X. Tian, CrystEngComm 14 (2012) 5836-5844.

[23] X.B. Han, Y.G. Li, Z.M. Zhang, H.Q. Tan, Y. Lu, E.B. Wang, J. Am. Chem. Soc. 137 (2015) 5486-5493.

[24] N. Li., B. Mu. L. Lv, R.D. Hang, J. Solid State Chem. 226 (2015) 88-93.

[25] A.X. Tian, J. Ying, J. Peng, J.Q. Sha, Z.G. Han, J.F. Ma, Z.M. Su, N.H. Hu, H.Q. 
Jia, Inorg. Chem. 47 (2008) 3274-3283.

[26] Z.M. Zhang, T. Zhang, C. Wang, Z.K. Lin, L.S. Long, W.B. Lin, J. Am. Chem. Soc. 137 (2015) 3197-3200.

[27] H.Y. An, Y.G. Li, D.R. Xiao, E.B. Wang, C.Y. Sun, Cryst. Growth Des. 6 (2006) $1107-1112$.

[28] S.Z. Li, P.T. Ma, J.P. Wang, Y.Y. Guo, H.Z. Niu, J.W. Zhao, J.Y. Niu, CrystEngComm 12 (2010) 1718-1721.

[29] H.J. Pang, C.J. Zhang, D.M. Shi, Y.G. Chen, Cryst. Growth Des. 8 (2008) $4476-4480$.

[30] C.J. Zhang, Y.G. Chen, H.J. Pang, D.M. Shi, M.X. Hu, J. Li, Inorg. Chem. Commun. 11 (2008) 765-768.

[31] H. Abbas, C. Streb, A.L. Pickering, A.R. Neil, D.L. Long, L. Cronin, Cryst. Growth Des. 8 (2008) 635-642.

[32] S.B. Li, H.Y. Ma, H.J. Pang, L. Zhang, Cryst. Growth Des. 14 (2014) $4450-4460$.

[33] Y.F. Qi, E.B. Wang, J. Li, Y.G. Li, J. Solid State Chem. 182 (2009) 2640-2645.

[34] L. Klištincová, E. Rakovský, P. Schwendt, Inorg. Chem. Commun. 11 (2008) $1140-1142$.

[35] L.M. Zheng, Y.S. Wang, X.Q. Wang, J.D. Korp, A.J. Jacobson, Inorg. Chem. 40 (2001) 1380-1385.

[36] L. Wang, X.P. Sun, M.L. Liu, Y.Q. Gao, W. Gu, X. Liu, J. Cluster Sci. 19 (2008) $531-542$ 
[37] E. Rakovský, D. Joniaková, R. Gyepes, P. Schwendt, Z. Mička, Cryst. Res. Technol. 40 (2005) 719-722.

[38] H.X. Liu, J. Wang, Y.F. Li, F.F. Jian, J. Chem. Crystallogr. 41 (2011) 1254-1257.

[39] H.Y. Ma, X. Meng, J.Q. Sha, H.J. Pang, L.Z. Wu, Solid State Sci. 13 (2011) $850-854$.

[40] H.J. Pang, X. Meng, H.Y. Ma, B. Liu, S.B. Li, Z. Naturforsch. 2012, 67b, $855-859$

[41] G.C. Ou, L. Jiang, X.L. Feng, T.B. Lu, Dalton Trans. (2009) 71-76.

[42] L. Klištincová, E. Rakovský, P. Schwendt, G. Plesch, R. Gyepes, Inorg. Chem. Commun. 13 (2010) 1275-1277.

[43] M.V. Pavliuk, V.G. Makhankova, V.N. Kokozay, I.V. Omelchenko, J. Jezierska, A. Thapper, S. Styring, Polyhedron 88 (2015) 81-89.

[44] S.W. Lin, Q. Wu, H.Q. Tan, E. B. Wang, J. Coord. Chem. 64 (2011) 3661-3669.

[45] W.T. Hou, J.Y. Guo, Z.X. Wang, Y. Xu, J. Coord. Chem. 66 (2013) 2434-2443.

[46] L. Klištincová, E. Rakovský, P. Schwendt, Transition Met. Chem. 35 (2010) $229-236$.

[47] J.X. Lin, J. Lü, R. Cao, J.T. Chen, C.Y. Su, Dalton Trans. (2009) 1101-1103.

[48] T. McGlone, J. Thiel, C. Streb, D.L. Long, L. Cronin, Chem. Commun. 48 (2012) $359-361$

[49] W.T. Xu, F.L. Jiang, Y.F. Zhou, K.C. Xiong, L. Chen, M. Yang, R. Feng, M.C. Hong, Dalton Trans. 41 (2012) 7737-7745.

[50] X.M. Zhang, X.M. Chen, Inorg. Chem. Commun. 6 (2003) 206-209. 
[51] B.X. Dong, J. Peng, C.J. Gómez-García, S. Benmansour, H.Q. Jia, N.H. Hu, Inorg. Chem. 46 (2007) 5933-5941.

[52] Y.Q. Lan, S.L. Li, Z.M. Su, K.Z. Shao, J.F. Ma, X.L. Wang, E.B. Wang, Chem. Commun. (2008) 58-60.

[53] X.S. Qu, L. Xu, G.G. Gao, F.Y. Li, Y.Y. Yang, Inorg. Chem. 46 (2007) $4775-4777$.

[54] X.S. Qu, L. Xu, F.Y. Li, G.G. Gao, Y.Y. Yang, Inorg. Chem. Commun. 10 (2007) 1404-1408.

[55] X.L. Wang, C. Qin, E.B. Wang, Z.M. Su, Chem. Commun. (2007), 4245-4247.

[56] U. Beckmann, S. Brooker, Coord. Chem. Rev. 245 (2003) 17-29.

[57] J.G. Haasnoot, Coord. Chem. Rev. 200-202 (2000) 131-185.

[58] X.L. Wang, C. Qin, E.B. Wang, Z.M. Su, Y.G. Li, L. Xu, Angew. Chem. Int. Ed. 45 (2006) 7411-7414.

[59] Q.G. Zhai, X.Y. Wu, S.M. Chen, Z.G. Zhao, C.Z. Lu, Inorg. Chem. 46 (2007) $5046-5058$.

[60] G.M. Sheldrick, SHELXS97, Program for Crystal Structure Solution, University of Göttingen, Göttingen, Germany, 1997.

[61] G.M. Sheldrick, SHELXL97, Program for Crystal Structure Refinement, University of Göttingen, Göttingen, Germany, 1997.

[62] I.D. Brown, D. Altermatt, Acta Crystallogr. B 41 (1985) 244-247.

[63] Y.F. Qi, Y.G. Li, C. Qin, E.B. Wang, H. Jin, D.R. Xiao, X.L. Wang, S. Chang, Inorg. Chem. 46 (2007) 3217-3230. 
[64] C.J. Zhang, H.J. Pang, Q. Tang, H.Y. Wang, Y.G. Chen, Dalton Trans. 39 (2010) 7993-7999.

[65] B.X. Dong, J. Peng, A.X. Tian, J.Q. Sha, L. Li, H.S. Liu, Electrochim. Acta. 52 (2007) 3804-3812.

[66] P.P. Zhang, J. Peng, H.J. Pang, Y. Chen, M. Zhu, D.D. Wang, M.G. Liu, Y.H. Wang, Inorg. Chem. Commun. 13 (2010) 1414-1417.

[67] Y.Q. Jiao, C. Qin, H.Y. Zang, W.C. Chen, C.G. Wang, T.T. Zheng, K.Z. Shao, Z.M. Su. CrystEngComm 17 (2015) 2176-2189.

[68] B. Keita, A. Belhouari, L. Nadjo, R. Contant. J. Electroanal. Chem. 381 (1995) $243-250$. 